\title{
Microcontroller ATmega 328P and GSM Based Advanced Home Security System
}

\author{
C. Malarvizhi ${ }^{1}$, V. Kalaipoonguzhali ${ }^{2}$ and J. Anitha ${ }^{3}$ \\ ${ }^{1,2,3}$ University College of Engineering Thirukkuvalai, Anna University, India \\ ${ }^{1}$ malar89.pdy@gmail.com, ${ }^{2}$ kalai.poonguzhali@gmail.com, \\ 3 anithachristina12@gmail.com
}

\begin{abstract}
The main objective of this project is to provide an advanced home security system using microcontroller ATmega 328P, GSM module and chloroform gas. Home security is very important nowadays as the possibilities of theft are increasing day by day. There has been much research done on various types of Home Security systems like Sensor based Home security System, Face recognition, Finger print, Palm print and keypad activation for authentication and so on. Many technologies have been used to capture an unauthorized movement using CCTV cameras and motion cameras, but they were failing in stopping the theft from being happening. Overcoming these drawbacks, this project is used to catch the thief from escaping away. This system consists of ATmega 328P microcontroller, fingerprint sensor, DC gear motor, IR sensor, DC servo motor, buzzer, chloroform sprayer and GSM module. Whenever the IR sensor senses the thief entering into the room, the security system locks all the doors and windows. At the same time chloroform sprayer releases its gas inside the room and makes the thief goes into unconscious. Then the alarm present in the security system alert its surrounding peoples and also GSM module is used to communicate with the owner of the house and police station.
\end{abstract}

Keywords: Microcontroller, GSM (Global system for mobile communication), chloroform gas, Fingerprint sensor

\section{Introduction}

In this fast moving world, proportional to the rate of development, crime and theft rates are also increasing. Normally, theft can be varied into two cases: First one is Hi-Tech: Eg. Stealing precious gems from museums and big jewellery shops and the second one is OldSchool style: Eg. Breaking through windows, drilling through walls and breaking lockers. So we need to do some necessary steps to reduce crimes such as making a device which is used to secure the important properties (money, jewels, etc.), and make a strong alert system to suppress theft rates atleast to certain extent, should keep good communication with the owner and also it should arrest the thief who is trying to stole the public and private properties. In this project, a new and emerging concept offers a comfortable, convenient, and safe environment for the owner's and also it catches the thief escaping away. We mainly focus on the security of a home when the user is away from the place. The security system uses GSM technology to send SMS to the owner. Also the device sends SMS to the emergency number which is provided to the system.

\section{Literature Review}

Sheikh Izzal Azid and Sushil Kumar [1] has designed and tested a cost effective and SMS operated home security system with the GPRS network. The performances of commercially available sensors were studied for their feasibility before installation in the 
intelligent home. The operation of the home security has been tested on Vodafone- Fiji network for emergency and feedback responses for 25 samples. The GSM experiment showed that it takes about 8-10s for the security system to respond the occupant and relevant civil authorities in case of emergency and it takes about 18-22s for the occupant to switch and monitor lights.

Jayashri Bangali and Arvind Shaligram [2] suggest two methods for home security system. The first system uses web camera. Whenever there is a motion in front of the camera, it gives security alert in terms of sound and a mail is delivered to the owner. The second method sends SMS which uses GSM-GPS Module (SIM548C) and LPC2148 microcontroller, sensors, relays and buzzers.

Internet of things (IoT) has been governing the electronics era with cloud services dominating the ever increasing electronics product segment. Security and safety has always become a basic necessity for urban population. Safa.H, Sakthi Priyanka.N, Vikkashini Gokul Priya.S, Vishnupriya.S and Boobalan.T [3] proposes a novel security system based on open source cloud server "thingspeak.com" and a low cost ESP8266 WiFi module. The project includes a PIR module which constantly monitors the home or work place. When the PIR module detects an intruder it sends a signal to the ATmega328P microcontroller. The System transmits an alert signal to the open source cloud which provides an alert signal on the user mobile phone. The system also employs a thumb print reader RS305 which controls the opening and the closing of a safety locker door. Thus the system uses ESP8266 Wi-Fi module and ATmega 328P which control the security system from the user mobile phone by means of any device with a potential internet connection.

Visvakumar Aravinthan, Vinod Namboodiri, Samshodh Sunku, and Ward Jewell [4] present a secure framework for smart metering in a wireless home area network scenario. Such framework was designed by first examining the communication requirements for AMI (Advanced metering Infrastructure) in the WHAN-SM scenario.

Santoso Budijono, Jeffri Andrianto and Muhammad Axis Novradin Noor [5] have designed and implemented a Home Security System. It can monitor the home area that is surrounded by PIR sensor and sending SMS, save images captured by the camera, and make people panic by turning on the buzzer when the PIR sensor senses any human presence.

\section{Existing System}

This existing system consists of PIR sensor, Buzzer, GSM module, microcontroller, camera and PC. The power supply unit provides supply to all the units. The PIR sensor is used to detect the presence of a person in the house. If the PIR sensor senses any human presence, it sends that information to the controller. A camera which is connected to the computer continuously monitors inside the house. The human presence is captured and compared with the stored images in PC. If the image is matched, the GSM will not send any SMS to the owner, else it sends an SMS to the owner. Some of the disadvantages of the existing system are low security, requires PC and camera which increase the circuit complexity and it can only monitor the thief movement but cannot arrest the thief from escaping away. 


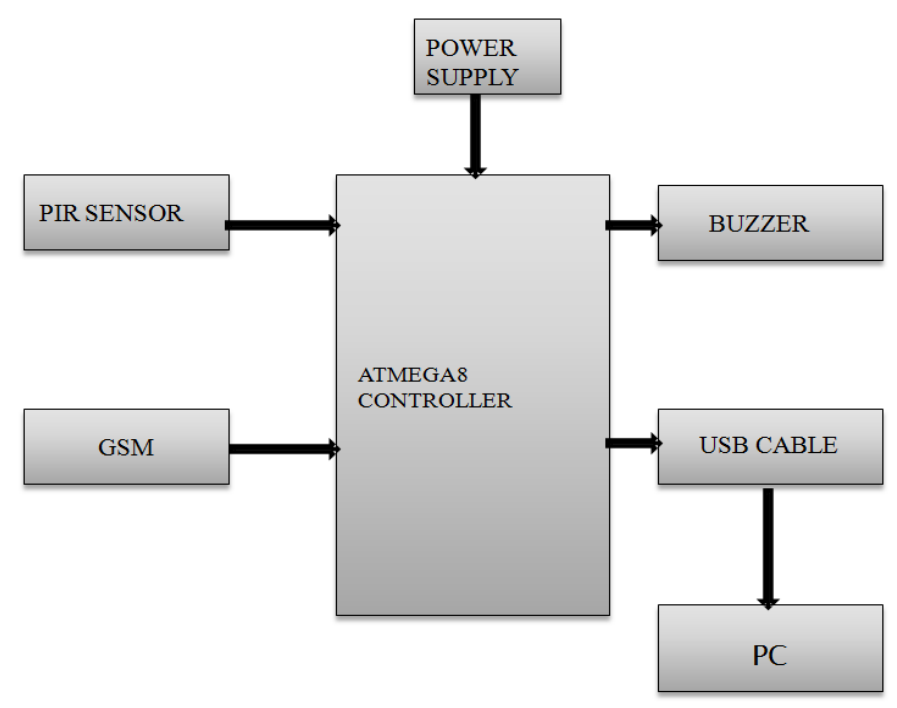

Figure 1. Block Diagram of Existing System

\section{Proposed System}

The proposed system consists of microcontroller, fingerprint sensor, keypad, DC gear motor, IR sensor, DC servo motor, buzzer, chloroform sprayer and GSM module. The fingerprint pattern of house members are already stored into the memory. A person has to verify his fingerprint pattern using fingerprint sensor. If the fingerprint is matched, then he has to enter the password. If the password is correct, then the door will be automatically opened. If any unauthorized person tries to break the door and enters into the house, the IR sensor will detect the presence of that person and send it to the controller. The controller automatically locks all the doors and windows and at the same time chloroform sprayer releases its gas in the room which makes the thief goes into an unconscious state. Then the buzzer will alert its surrounding peoples and also GSM module is used to communicate with the owner of the house and the nearby Police station.

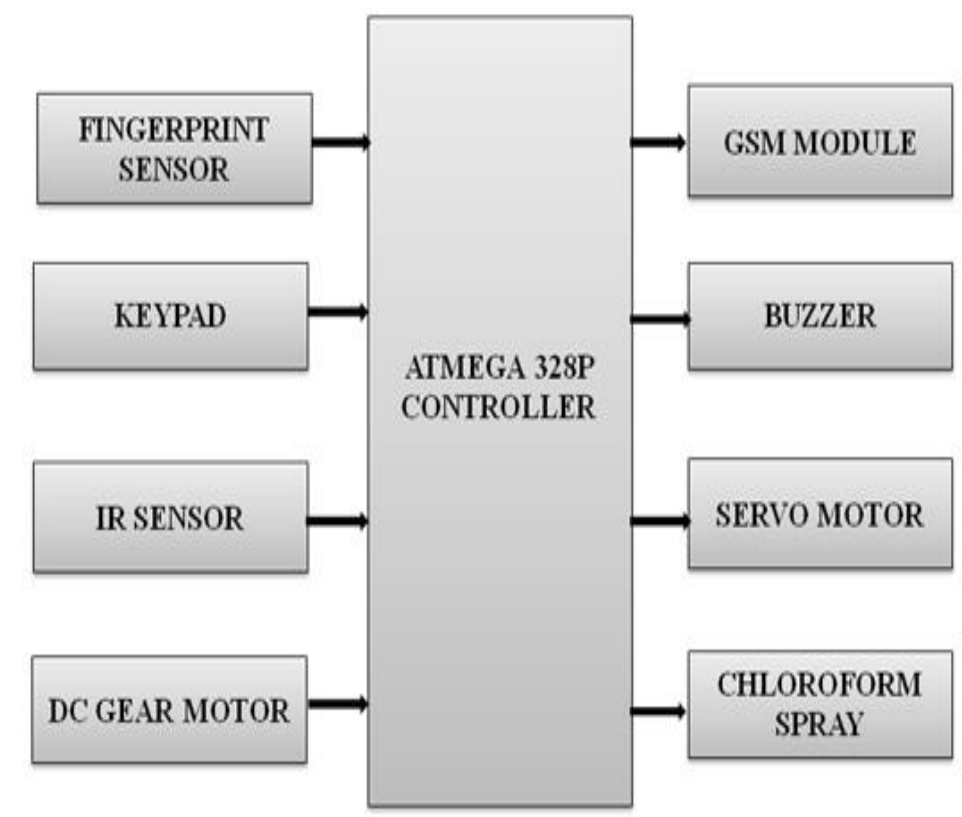

Figure 2. Block Diagram of Proposed System 


\section{Schematic Diagram}

The schematic diagram of the proposed system is shown in Figure 3. The figure clearly shows that how the sensors, motors, GSM module and chloroform sprayer are connected to the pins of microcontroller.

Some of the advantages of proposed system are,

1. It provides higher security.

2. It can be used to automate the door locking process. So the user need not to carry the door key along with him, he can just remember the password and use it later on to open the door.

3. This system uses commonly available components.

4. Simple and easy to implement

5. Automatic dialing and alert system

6. Easy thief catcher

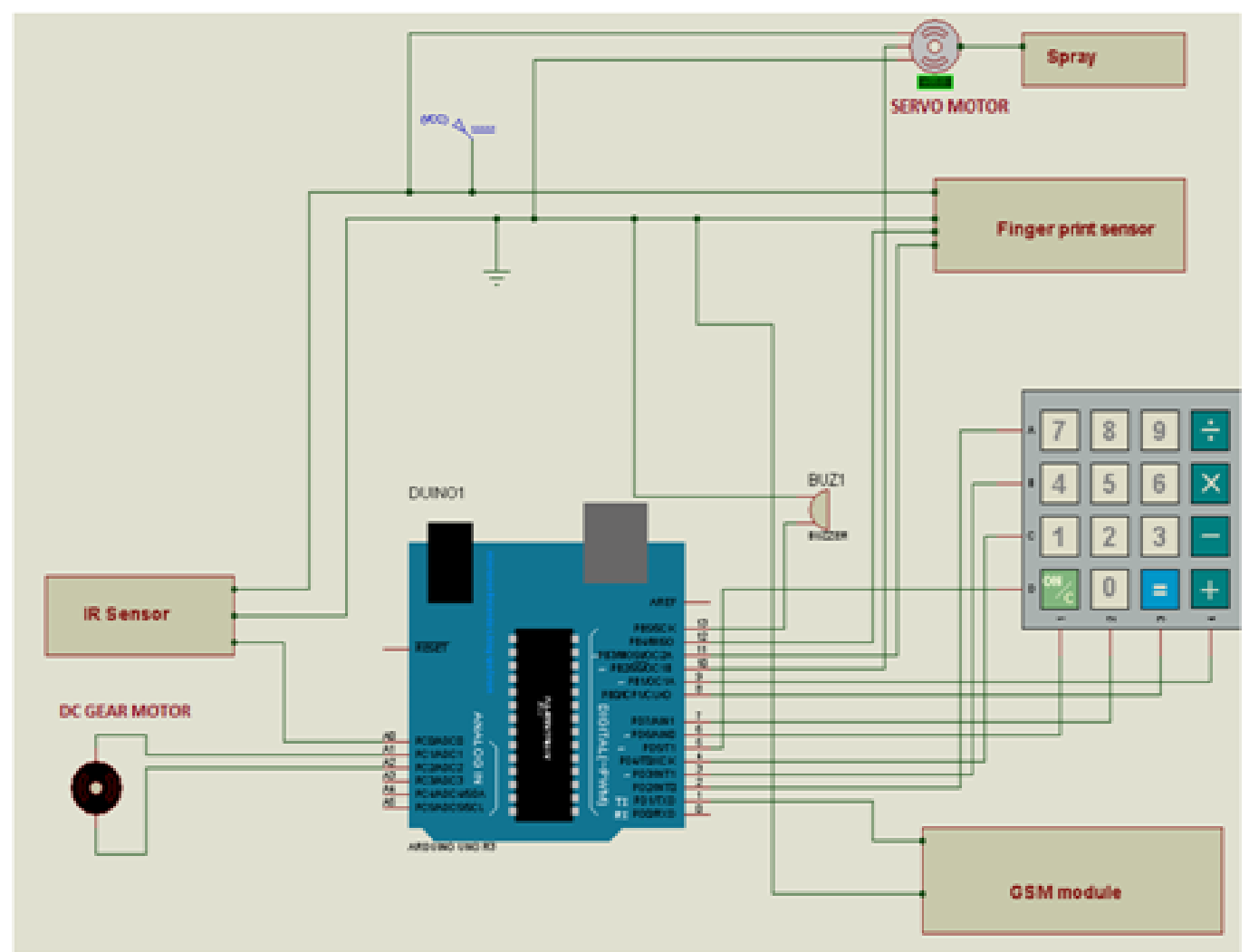

Figure 3. Schematic Diagram of Proposed System

\section{Flow Chart}

The flow chart of the proposed system involves the following process. Process 1 shows the entry of an authorized person and process 2 shows the entry of an unauthorized person. 


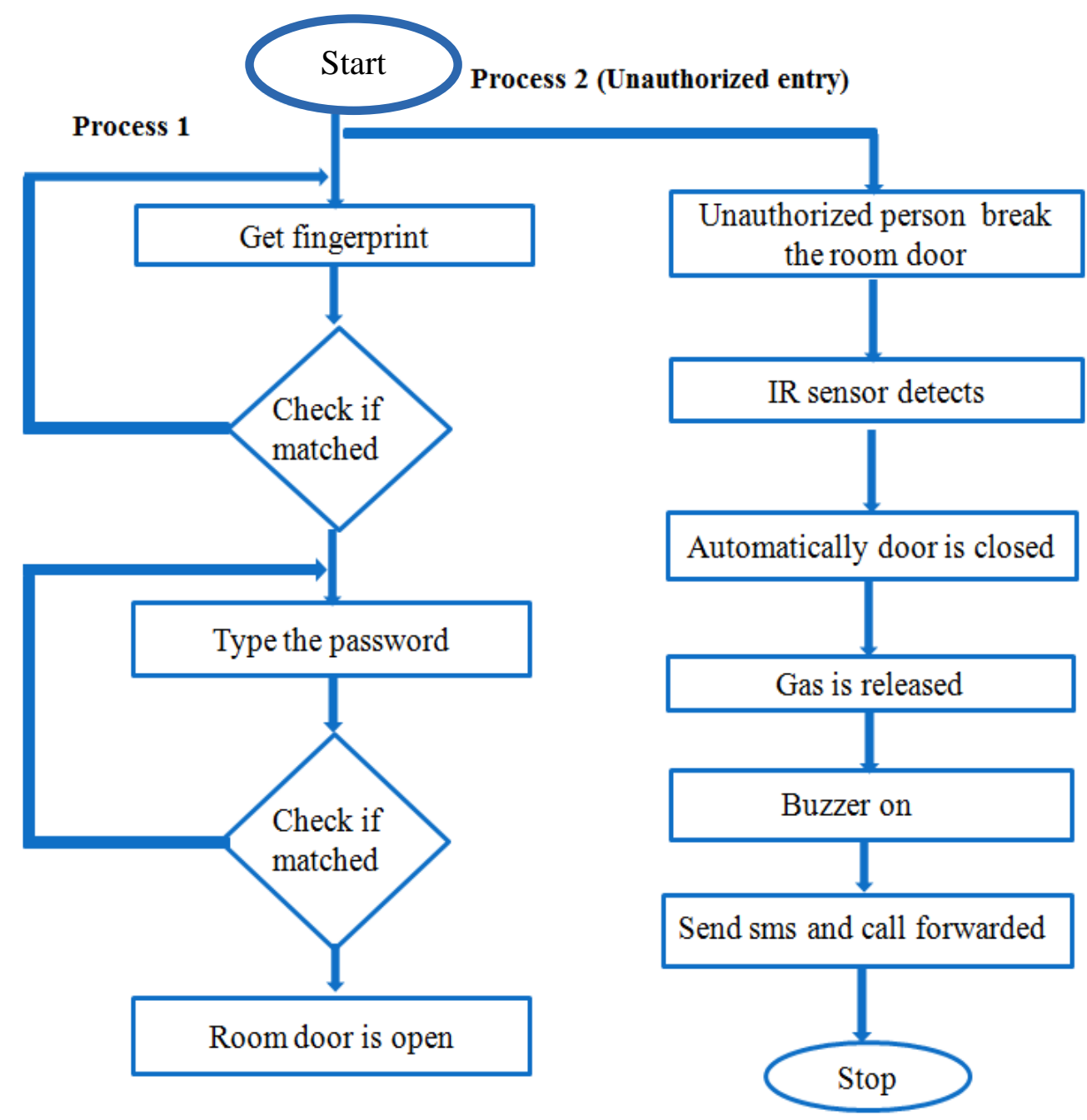

Figure 4. Flow Chart of the Proposed System

\section{Hardware Description}

\subsection{ATmega 328P Microcontroller}

The high-performance Microchip Pico power 8-bit AVR RISC-based microcontroller combines 32KB ISP flash memory with read-while-write capabilities, 1024B EEPROM, 2KB SRAM, 23 general purpose I/O lines, 32 general purpose working registers, three flexible timer/counters with compare modes, internal and external interrupts, serial programmable USART, a byte-oriented 2-wire serial interface, SPI serial port, a 6channel 10-bit A/D converter (8-channels in TQFP and QFN/MLF packages), programmable watchdog timer with internal oscillator, and five software selectable power saving modes. The device operates between 1.8-5.5 volts.

\subsection{Fingerprint Sensor}

A fingerprint sensor is an electronic device which is used to capture a digital image of the fingerprint pattern. The distinguishing features of fingerprint pattern are extracted and a biometric template is created. This biometric template is stored in a memory and will be used for matching. There are many technologies available including optical, capacitive, RF, thermal, piezoresistive, ultrasonic, piezoelectric and MEMS. Each technology has its own merits and demerits. In this project, optical fingerprint sensor is used. 


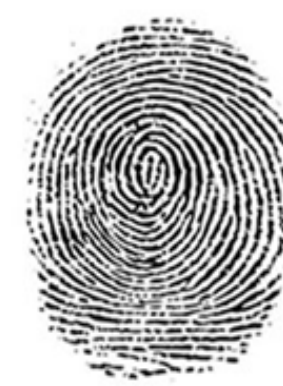

Digital Image of the Fingerprint pattern

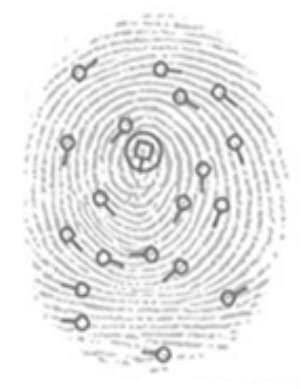

Distinguishing and unique features of Fingerprint pattern

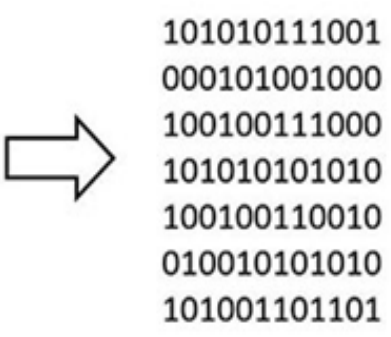

Digital Template of the Pattern stored in memory

\section{Figure 5. Digital Form of Fingerprint Pattern}

\subsection{Gear Motor and Servo Motor}

A geared DC Motor is similar to DC motor with gear assembly attached to the motor. The speed of motor is counted in terms of rotations of the shaft per minute and is termed as RPM. The gear assembly is mainly used to increase the torque and reduce the speed. Using the correct combination of gears, its speed can be reduced to any desirable value. The main function of the DC gear motor in this project is to control the door (open and close) automatically.

A servomotor is a special type of motor which is used for precise control of angular or linear position, velocity and acceleration. Some of the applications of servomotors are robotics, CNC machinery or manufacturing. In this project, servomotor is used to control the chloroform sprayer.

\subsection{IR Sensor}

The main function of IR sensor is to detect the presence of intruder. It consists of IR transmitter and IR receiver. The basic concept of IR (infrared) intruder detector is to transmit the IR signal (radiation) in a direction and a signal is received at the IR receiver when the IR radiation bounces back from a surface of the object.

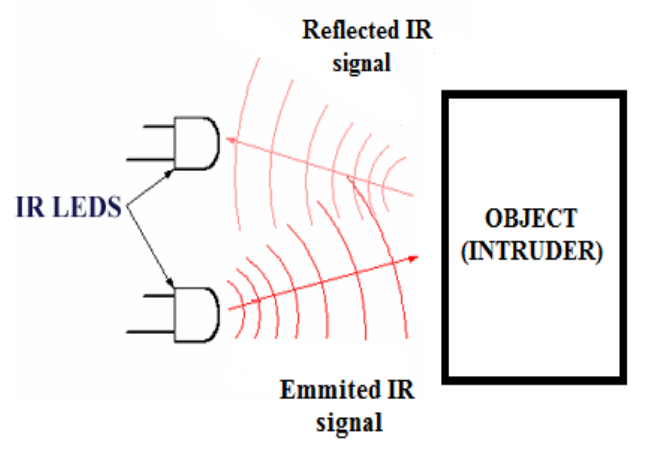

Figure 6. Illustration of IR Transmission

\subsection{Chloroform Spray}

Chloroform is also known as trichloromethane. It is an organic compound with formula $\mathrm{CHCl}_{3}$. Small amounts of chloroform can induce lethargy and disorientation. Increased exposure leads to unconsciousness and an inability to feel pain. From the moment of unconsciousness, there is generally a 10-15 minute where a person is asleep. For 
implementation, chloroform gas is not used. This project is tested with normal perfume spray.

\subsection{GSM (Global System for Mobile Communication)}

GSM stands for Global System for Mobile Communication. A GSM module works like a mobile phone which accepts a SIM card, and operates over a subscription to a mobile operator. When a GSM modem is connected to the controller, it allows the controller to use the GSM modem to communicate over the mobile network. This GSM modem is used to alert the owner and police station through call and SMS respectively.

\subsection{Buzzer}

Buzzer is also known as beeper. It is an audio signaling device. The types of buzzer includes mechanical, electromechanical, and piezoelectric. In this project, piezoelectric buzzer is used which alert the surrounding peoples. Some of the applications of piezoelectric buzzer includes alarm devices, timers, confirmation of user input (ex: mouse click or keystroke), electronic metronomes, game shows, sporting events and household appliances.

\section{Hardware Implementation}

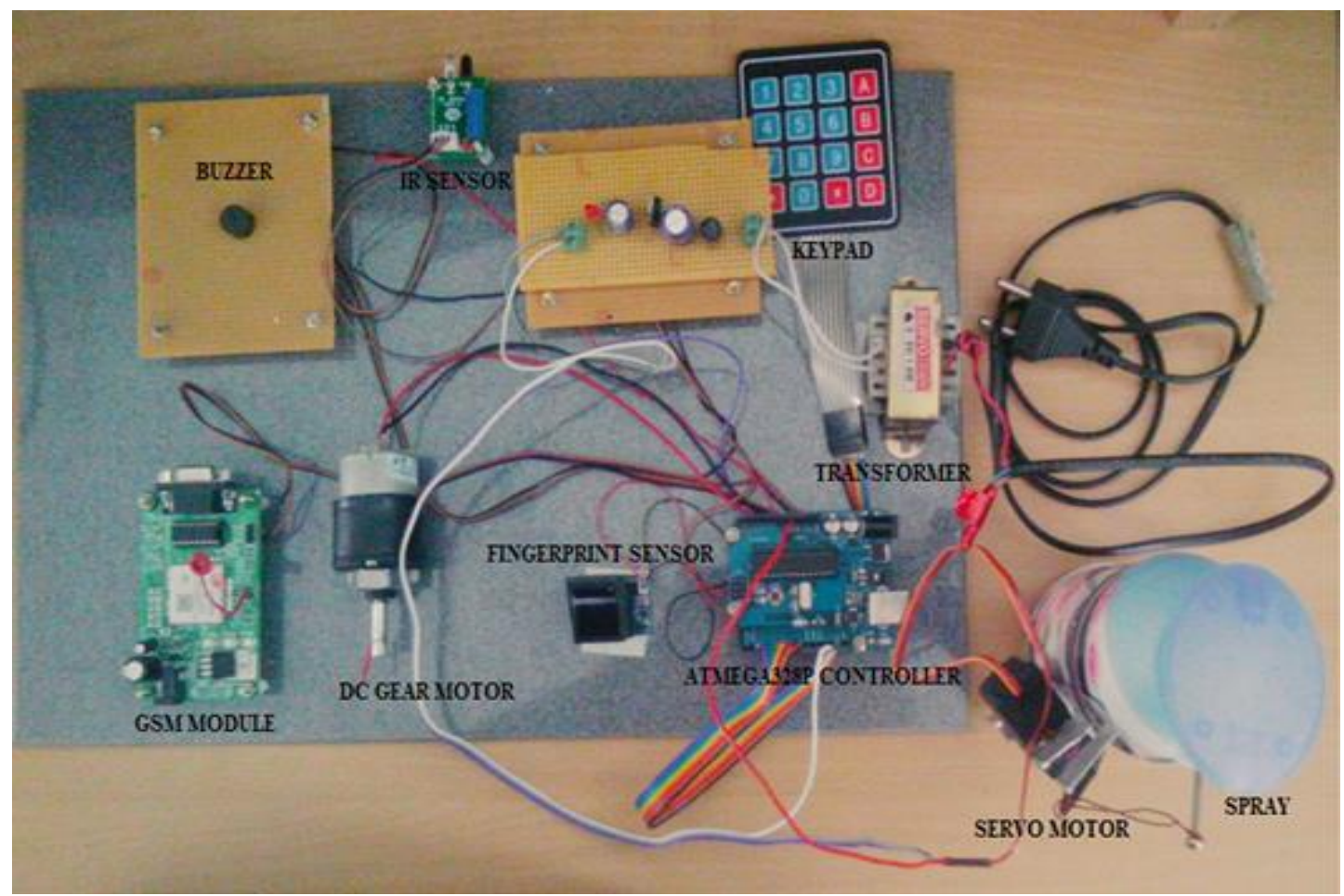

Figure 7. Implementation of Hardware

\section{Conclusion}

With the help of this project, we can provide higher security to homes. Here we have used both fingerprint and password for authentication; hence we can reduce the probability of hacking. This project also helps us to catch the thief inside the room using chloroform gas and communicate the house owner and police station though GSM. 


\section{Future Enhancement}

We can use face recognition instead of fingerprint identification to further increase the security. This security system can also be implemented using IOT which connects globally. By doing simple modification in this system, it can also be used for providing security in Banks, jewelry shops, ATM centers, R\&D laboratories and the places where high security is needed.

\section{References}

[1] S. Izzal Azid and S. Kumar, "Analysis and Performance of a Low Cost SMS Based Home Security System”, International Journal of Smart Home, vol. 5, no. 3, (2011) July, pp. 15-24.

[2] J. Bangali and A. Shaligram, "Design and Implementation of Security Systems for Smart Home based on GSM technology", International Journal of Smart Home, vol. 7, no. 6, (2013), pp. 201-208.

[3] H. Safa, N. Sakthi Priyanka, S. Vikkashini Gokul Priya, S. Vishnupriya and T. Boobalan, "IOT based Theft Premption and Security System", International Journal of Innovative Research in Science, Engineering and Technology, vol. 5, no. 3, (2016) March, pp. 4312-4317.

[4] V. Aravinthan, V. Namboodiri, S. Sunku and W. Jewell, "Wireless AMI Application and Security for Controlled Home Area Networks", IEEE, (2011), pp. 1-8.

[5] S. Budijono, J. Andrianto and M. Axis Novradin Noor, "Design and implementation of modular home security system with short messaging system", EDP Sciences, (2014), pp. 1-5.

[6] R. Kharik Abhishek, C. Archana and R. R. Bhambare, "A Smart Home Security System Based On Arm7 Processor", International Journal of Engineering and Computer Science, ISSN:2319-7242, vol. 3, no. 4, (2017) April, pp. 5283-5287.

[7] L. Zoref, D. Bregman and D. Dori, "Networking Mobile Devices and Computers in an Intelligent Home", International Journal of Smart Home, vol. 3, no. 4, (2009) October, pp. 15-21.

[8] R. J. Robles and T. Kim, "Review: Context Aware Tools for Smart Home Development", International Journal of Smart Home, vol. 4, no. 1, (2010) January, pp. 1-11.

[9] Y. Zhao and Z. Ye, "Low cost GSM/GPRS BASED wireless home security system", IEEE Trans. Consumer Electron, vol. 56, no. 4, (2007) January, pp. 546-567.

[10] Z. Bing, G. Yunhung, L. Bo, Z. Guangwei and T. Tian, "Home Video Security Surveillance", Info-Tech and Infonet, Proceedings, ICII 2001-Beijing. 2001 International Conference, vol. 3, (2011), pp. 202-208.

[11] M. Meyer, M. Hotter and T. Ohmacht, "A new system for Video-based Detection of moving objects and its integration into digital networks", Security Technology 1996, 30th Annual 1996 International Carnahan Conference, (1996), pp. 105-110.

[12] M. Butt, M. Khanam, A. Khan, M. Sikandar and H. Khiyal, "Controlling Home Appliances Remotely Through Voice Command", (IJACSA) International Journal of Ad-vanced Computer Science and Applications, Special Issue on Wire-less \& Mobile Networks, pp. 35-39.

[13] G. M. S. M. Rana, A. A. M. Khan, M. N. Hoque and A. F. Mitul, "Design and Implementation of a GSM Based Remote Home Security and Appliance Control System", Proceedings of the 2nd International Conference on Advancesin Electrical Engineering, Dhaka, (2013) December 19-21, pp. 291-295.

[14] A. W. Ahmad, N. Jan, S. Iqbal and C. Lee, "Implementation of ZigBee-GSM Based Home Security Monitoring and Remote Control System", IEEE 54th International Midwest Symposium on Circuits and Systems, Seoul, (2011) August 7-10, pp. 1-4.

[15] L. AlAbdulkarim and Z. Lukszo, "Integrating Information Security Requirements in Critical Infrastructures: Smart Metering Case", International Journal of Critical Infrastructures, vol. 6, no. 2, (2010).

[16] Z. Shunyang, X. Du, J. Yongping and W. Riming, "Realization of Home Remote Control Network Based on ZigBee", Proceedings of the 8th International Conference on Electronic Measurement and Instruments, Xian, China, (2007) August 16-18.

[17] A Fang, X. Xu, W. Yang and L. Zhang, "The Realization of Intelligent Home by ZigBee Wireless Network Technology", Proceedings of the 2009 Pacific-Asia Conference onCircuit, Communications and System, Chengdu, China, (2009) May 16-17.

[18] J. W. H. Qin, "The Design of Wireless Intelligent Home System Base on ZigBee”, Proceedings of the 11th International Conference on Communication Technology, Hangzhou, China, (2008) November 1012.

[19] N. Sriskanthan, F. Tan and A. Karande, "Bluetooth based home automation system", Microprocessors and Microsystems, vol. 26, no. 6, (2002), pp. 281-289.

[20] M. Ghahramanian Golzar and H. Tajo zzakerin, "A New Intelligent Remote Control System for Home Automation and Reduce Energy Consumption", Fourth Asia International Conference on Mathematical/Analytical Modeling and Computer Simulation, (2010), pp 174-180.

[21] X. Zeng, A. O. Fapojuwo and R. J. Davies, "Design and Performance Evaluation of Voice Activated Wireless Home Devices", IEEE Transactions on Consumer Electronics, vol. 52, no. 3, (2006) August. 
[22] A. O. Oke, O. M. Olaniyi, O. T. Arulogun and O. M. Olaniyan, "Development of a MicrocontrollerControlled Security Door System", Pacific Journal of Science and Technology, vol. 10, no. 2, (2009), pp. 398-403.

[23] G. K. Verma and P. Tripathi, "A Digital Security System with Door Lock System Using RFID Technology”, International Journal of Computer Applications (0975 -8887), vol. 5, (2010), pp. 6-8.

\section{Authors}

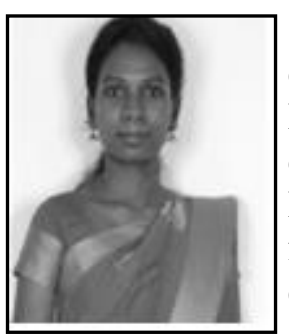

C. Malarvizhi, received her bachelor's degree in electronics and communication engineering from Pondicherry University, Pondicherry, India in 2010, and her master's degree in wireless communication from Pondicherry engineering college, Pondicherry, India in 2012.Currently she is working as teaching fellow in the department of electronics and communication engineering, university college of engineering, Thirukkuvalai (A constituent college of Anna university, Chennai, India).Her research interests include wireless security, MIMO wireless communications, and Distributed antenna system (DAS).

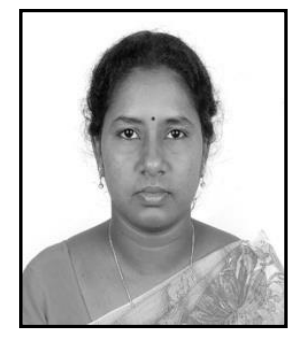

V. Kalaipoonguzhali, received bachelor's in Electronics and Communication Engineering and master's in Power Electronics and Drives from Anna University, India. Currently she is pursuing $\mathrm{PhD}$ and working as Teaching Fellow in the Department of Electronics and Communication Engineering at University College of Engineering Thirukkuvalai (A Constituent College of Anna University, Chennai, India). Her research interests include Wireless Communication and Digital Signal Processing.

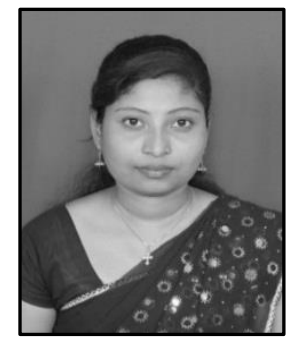

J. Anitha born in 1986, working as Teaching Fellow in the Department of Electrical and Electronics Engineering, University College of Engineering Thirukkuvalai (A Constituent College of Anna University, Chennai, India). She received her bachelor's in Electrical and Electronics Engineering in 2009 and Master's in Power System Engineering from Anna University, India. Her research interest includes renewable energy sources and power system applications. 
International Journal of Smart Home

Vol. 11, No. 6 (2017) 